\title{
Крылатые единицы литературного происхождения в православных медиатекстах
}

\section{Winged Units of Literary Origin in Orthodox Media Texts}

\author{
Светлана Викторовна Дудушкина, Ольга Валентиновна \\ Ломакина, Александра Стефановна Макарова \\ (Москва, Россия)
}

\section{Абстракт:}

Статья посвящена крылатым единицам, восходящим к русской литературе и используемым в текстах современного православного медиадискурса. Литература, оставаясь одним из главных источников появления крылатых единиц, оспаривает своё первенство у синтетических жанров (кино, телевидение, эстрада и т. д.) и языка рекламы. Подробный анализ источников крылатых единиц, пришедших из русской литературы, позволяет детально исследовать не только наиболее часто употребляемые православными авторами крылатые единицы, но и особенности этого функционирования. Лингвопрагматика крылатых единиц обнаруживается через их особую экспрессию и способность сжато выразить ту или иную мысль, что позволяет говорить о том, что они представляют собой своеобразный конденсат идей. Однако их роль и функционирование в современном православном медиадискурсе пока не изучались.

\section{Ключевые слова:}

православный медиадискурс; медиатекст; крылатика; крылатые единицы

1 Исследование выполнено при финансовой поддержке РФФИ в рамках научного проекта № 17-29-09064. 


\section{Abstract:}

The article is devoted to winged units dating back to Russian literature and used in the texts of modern Orthodox media discourse. Remaining one of the main sources of the winged units, literature contends for primacy with synthetic genres (cinema, television, estrade, etc.) and the language of advertising. A detailed analysis of the sources of winged units, come from Russian literature, allows us to examine in detail not only the winged units most frequently used by Orthodox authors, but also the features of this functioning. Linguo-pragmatics of winged units is revealed through their special expression and ability to succinctly convey a particular thought; thus, they represent a kind of condensate of ideas. The high demand on winged word studying can be explained by the fact that this part of Phraseology is very quickly moving on and is being filled and renewed very fast. The transformation potential of winged words makes it possible for journalists to use them in a strong text position-in heading. Being the headline the language units have a special communicative loading as the headline is the main tool of the author's position. However, their role and functioning in the modern Orthodox media discourse has not yet been studied.

\section{Key words:}

Orthodox Media Discourse; Media Text; Krylatika; Winged Units

\section{Введение}

Изменения, происходящие в социально-политической сфере, влекут за собой модификации в информационном пространстве. Развитие научно-технического прогресса непрестанно способствует расширению знаний человека об окружающем мире. Данные процессы оказывают влияние в той или иной степени на мировосприятие людей, на их отношение к событиям и возникающим проблемам в жизни общества, вместе с тем «эффективность или неэффективность концептуального взаимодействия индивидов зависит от различных факторов онтологии мира, сознания и языка в процессе вербального общения» ${ }^{2}$.

Известно, что сегодня интернет является самым популярным способом коммуникации, так как использование такого вида коммуникативной связи делает общение людей глобальным, стирает пространственные и даже временные

2 BOLSUNOVSKAJA, L. M.: Metadiskurs: traktovki ponjatija i napravlenija issledovanija. In: ROMANOVA, T. V. (red.): Kognitivnyje issledovanija jazyka. Nižnij Novgorod: Izdatel'stvo DEKOM, 2019, s. 667 . 
границы. Интернет-пространство так же активно развивается, предоставляя пользователям всё новые неограниченные возможности. Результатом такого развития стал активный процесс перемещения коммуникации в виртуальное пространство, что сделало интернет-текст или медиатекст предметом изучения.

\section{История вопроса}

Дискурс является центром современных лингвистических исследований не случайно, ибо этот термин «понимается как единство двух сущностей процесса языковой коммуникации и получающегося в ее результате объекта, т. е. текста. Благодаря такому двуединству, дискурс можно изучать и как разворачивающийся во времени процесс, и как структурный объект. „Дискурс“ это максимально широкий термин, включающий все формы использования языка» ${ }^{3}$.

Сегодня уже медиадискурс - одно из приоритетных направлений не только дискурсологии, но и современного российского и зарубежного языкознания. Благодаря таким свойствам, как гетерогенность, поликодовость и полимодальность, в нём соединены разные системы: с одной стороны, вербальная, с другой - семиотическая. Этот тип дискурса представлен в текстах разных стилистических разновидностей - от публицистического до религиозного.

Особый интерес у современных российских лингвистов (Е.В.Бобырева, И. В. Бугаева, Т. В. Ицкович, А. С. Макарова, А. В. Полонский, В. И. Постовалова и др.) вызывает религиозный дискурс, отличающийся языковыми и интертекстуальными особенностями. На фоне углубления разного рода знаний знание о Боге - это, скорее, возвращение к истокам, к утраченному знанию в силу исторических, социальных, политических и других причин. Возвращение или возрождение этого знания нам видится одной из основных задач православного дискурса. Как показывают исследования ${ }^{4}$, именно православный медиадискурс способен реализовать эту сложную задачу, поскольку, в отличие от религиозного дискурса, который осуществляется непосредственно в институте Церкви (храмы, конференции, форумы священства и т. д.), православный медиадискурс имеет неограниченное количество пользователей в интернет-пространстве: интернет-версии православных журналов и газет, интернет-порталы и сайты,

3 KIBRIK, A. A.: Modus, žanr i drugije parametry klassifikacii diskursov. Voprosy jazykoznanija, 2009, № 2, s. 3 .

4 KUNYGINA, O. V., LOMAKINA, O. V., MAKAROVA, A. S.: Orthodoxy and the World Website as an Example of Modern Religious Discourse. The European Proceedings of Social \& Behavioural Sciences, No 59, p. 507-514. 
православные социальные сети, аудио и видеотрансляции православных радио («Вера», «Радонеж» и пр.) и телевидения («Союз», «Спас» и пр.).

В связи с появлением новых каналов коммуникации лингвистический вектор смещается на вопросы интернет-речетворчества, речевого поведения коммуникантов в сети, на особенности языка онлайн-общения, отличающегося смешением стилистических регистров, особой экспрессией, которую в первую очередь создают лексико-фразеологические средства.

Предметом данной статьи является крылатика, восходящая к русской литературе XIX-XX вв., то есть фонд крылатых единиц (далее КЕ) литературного русского языка с известным источником и временным отрезком происхождения. Следует отметить, что интерес к крылатым единицам возник достаточно давно, однако до сих пор данные устойчивые языковые единицы остаются на периферии фразеологических исследований, хотя «формирование фонда крылатых единиц - процесс постоянный, что отражает незамкнутость крылатики» ${ }^{5}$. Вместе с тем фразеографические сборники включают в себя многие крылатые слова, пришедшие из античной литературы, Библии, фольклора и классической литературы. По мнению С. Г. Шулежковой, «с конца XVIII в. до начала XX в. русская художественная литература становится самым мощным источником крылатых выражений» ${ }^{6}$. Однако следует отметить, что без должного внимания остаются контекстуальные особенности и интертекстуальный характер фразеологических средств православной коммуникации.

\section{Методология исследования}

В работе мы опирались на теоретические труды Петербургской фразеологической школы профессора В. М. Мокиенко, Магнитогорской научной словарной лаборатории профессора С. Г. Шулежковой, Костромской фразеологической школы профессора А. М. Мелерович и других фразеологов. Основными методами исследования являются описательно-аналитический, который предусматривает анализ функционирования крылатики в конкретном употреблении, систематизацию приёмов трансформаций устойчивых языковых единиц и обобщение данных, полученных при рассмотрении примеров трансформационного потенциала крылатики в медиатекстах, функционально-контекстологический для отслеживания закономерностей употребления преобразований крылатики; использовались функциональный и тематический подходы для анализа

5 LOMAKINA, O. V., MOKIENKO, V. M.: Winged words in a modern cultural context. RUDN Journal of Language Studies, Semiotics and Semantics, № 10 (2), p. 262.

6 ŠULEŽKOVA, S. G.: Krylatyje vyraženija russkogo jazyka, ich istočniki i razvitije. Moskva: «Azbukovnik», 2002, s. 86. 
медиаконтента и приём сплошной выборки контекстов на сайте православного журнала «Фома» ${ }^{7}$.

Верификация и паспортизация эмпирического материала была проведена по следующим авторитетным фразеографическим источникам: «Большой словарь крылатых слов и выражений русского языка» В. П. Беркова, В. М. Мокиенко, С.Г.Шулежковой (2005), словарь «И жизнь, и слёзы, и любовь..» Происхождение, значение, судьба 1500 крылатых слов и выражений русского языка С.Г.Шулежковой (2011) и учебный словарь-справочник «Горе от ума» А. С. Грибоедова: цитаты, литературные образы, крылатые выражения» В. М. Мокиенко, О. П. Семенец, К. П. Сидоренко (2009).

\section{Анализ материала}

Эмпирическим материалом для статьи послужили заголовки публикаций православного журнала «Фома», так как «именно заголовок [...] является главным средством выражения авторской позиции, т. е. основной сильной позицией текста» ${ }^{8}$.

Нами были отобраны заглавия, включающие КЕ, восходящие к русской литературе XIX-XX вв. Приёмом сплошной выборки на сайте журнала «Фома» было обнаружено более 100 заголовков, которые содержат КЕ литературного русского языка как в инвариантном виде, так и в трансформированном. Материалом данной статьи послужило 15 заголовков, включающих КЕ, источниками которых являются произведения русской литературы XIX-XX вв. XIX век представлен Н. В. Гоголем (3 примера), М. Ю. Лермонтовым (2 примера), Ф. М. Достоевским, А. С. Грибоедовым, А. С. Пушкиным, И. С. Тургеневым. Творчество Е.Л.Шварца (2 примера), М. Горького, А. С. Грина, И. А. Ильфа и Е. Петрова относится к XX веку.

Трансформационный потенциал крылатики в контексте представляет собой один из научных векторов фразеологических исследований, результаты которых отражены в трудах О. В. Ломакиной, А. С. Макаровой, А. М. Мелерович, В.М. Мокиенко и др. Соответственно при анализе отобранных заголовков мы опирались на классификацию трансформаций фразеологизмов русского языка, предложенную А.М.Мелерович и В.М.Мокиенко. Авторы словаря «Фразеологизмы в русской речи» (2005) выделяют два основных типа индиви-

7 Žurnal Foma. <https://foma.ru/arhiv>. [online]. [cit. 10. 5. 2020].

8 LOMAKINA, O. V.: Krylatyje jedinicy $v$ roli sovremennogo gazetnogo zagolovka: sostav, tendencii upotreblenija. Russkij jazyk za rubežom, № 1, 2019, s. 37 . 
дуально-авторских преобразований: семантические и структурно-семантические 9 .

В количественном отношении трансформы в роли заголовков статей встречаются гораздо чаще (12 из 15 примеров), чем инварианты (3 из 15).

В начале приведём примеры, не содержащие структурно-семантические трансформации заглавий, где присутствуют два типа семантических преобразований фразеологических единиц: буквализация значения, когда «прямое значение сочетания, представляющее собой образную основу фразеологических единиц, не только актуализируется, но выступает на первый план, часто противопоставляясь фразеологическому значению оборота» ${ }^{10}$ и контекстуальное изменение плана содержания КЕ.

На дне. История города, погребенного Рыбинским водохранилищем (№ 2 (106) - 2012). Здесь наблюдается приём буквализации через контекст, так как в результате создания Рыбинского водохранилища город Молога оказался на его дне.

Ср.: На дне - выражение - из назв. пьесы М. Горького «На дне» (1902), где изображена жизнь деклассированных людей, обитателей ночлежки. [...] Выражение, вероятнее всего, существовало и до появления пьесы, но именно пьеса Горького сделала его популярным ${ }^{11}$

Обыкновенное чудо (№ 1 (13) - 2002) - беседа с диаконом А. Кураевым о чудесах и о том, что «ОБЫЧНОЕ чудо, когда Господь помогает Своим людям, спасает их, исцеляет». Ни структура, ни семантика выражения не изменились.

Ср.: Обыкновенное чудо - название сов. худ. фильма реж. Х. А. Локшиной (1965) по одноименной пьесе Е. Л. Шварца $(1954)^{12}$.

Рога и копыта. Кто такие бесы, и нужно ли их бояться (№ 2 (58) - 2008). Ср.: Рога и копыта - так названа 15-я глава сатирического романа И. Ильфа и Е. Петрова «Золотой теленок» (1931), где рассказывается о фиктивной конторе по заготовке рогов и копыт, организованной великим комбинатором Остапом Бендером [...] Возможно, навеяно детской песенкой о сереньком козлике, откуда

9 MELEROVIČ, A. M., MOKIJENKO, V. M.: Frazeologizmy v russkoj reči: slovar': ok. 1ooo jedinic. Moskva: Russkije slovari: Astrel': AST, 2005.

10 Там же, с. 20.

11 BERKOV, V.P., MOKIJENKO, V. M., ŠULEŽKOVA, S. G.: Bol'šoj slovar' krylatych slov russkogo jazyka: ok. 4000 jedinic. Moskva: AST: Astrel': Russkije slovari, 2005, s. 293.

12 ŠULEŽKOVA, S. G.: «I žizn', i slezy, i ljubov'...» Proischoždenije, značenije, sud'ba 1500 krylatych slov i vyraženij russkogo jazyka. Moskva: FLINTA: Nauka, 2011, s. 488. 
возникло выражение остались рожки да ножки от кого-чего-л. - 'почти ничего не осталось ${ }^{13}$.

Данный пример отличает контекстуальное изменение семантики, понять которое помогает подзаголовок. Такой подзаголовок выступает в роли дополнительного названия и служит своеобразным «навигатором» публикации, благодаря чему возможен быстрый просмотр статьи. Как правило, подзаголовки разъясняют тематику публикации, привлекают внимание читателя, порой интригуют и подталкивают к прочтению напечатанного материала.

Теперь рассмотрим заголовки, в которых нами обнаружены структурно-семантические преобразования. В статье представим следующие типы: комплексный прием (7 примеров), лексическая субституция (4 примера), контаминация (1 пример), экспликация (1 пример) и грамматическое изменение (1 пример).

В заглавии Мятежный парус (№ 5 (109) - 2012) используется приём контаминации.

Ср.: А он, мятежный, просит бури - концовка романса «Парус», написанного на стихотворение М. Ю. Лермонтова $(1841)^{14}$.

Ср.: Белеет парус одинокий - начальная строка стихотворения М. Ю. Лермонтова «Парус» (1832) и одноименного романса (муз. А. Е. Варламова (1848), А. Г. Рубинштейн (1849)) $)^{15}$.

Публикация посвящена юбилею русского поэта Ю. Кублановского, название представляет собой авторскую метафору и даёт образную характеристику герою данной публикации.

Следующий пример содержит грамматическое изменение (жен. род меняется на муж. род) стержневого компонента КЕ бегущцая.

Бегущий по волнам (№ 3 (26) - 2005).

Ср.: Бегущая по волнам - от назв. повести А. С. Грина «Бегущая по волнам $(1928) \gg{ }^{16}$.

В данном случае подзаголовок - Автор «Альх парусов» в поисках веры помогает читателю понять, что речь пойдет о писателе А. Грине.

Используя разные приёмы трансформаций КЕ, журналисты актуализируют схожие мысли в приведённых выше примерах: творческие люди ассоциируются с поэтическими образами.

Приём лексической субституции представлен 4 заголовками.

13 BERKOV, V.P., MOKIJENKO, V. M., ŠULEŽKOVA, S. G.: Bol’šoj slovar' krylatych slov russkogo jazyka: ok. 4 ooo jedinic. Moskva: AST: Astrel': Russkije slovari, 2005, s. 428.

14 Там же, с. 28.

15 Там же, с. 43.

16 Там же, с. 39. 
Обыкновенное хамство (№ 11 (79) - 2009) - о людском пороке под названием хамство, которое получило такое название по имени сына Ноя Хама, смеявшегося над наготой пьяного отца. Заменив стержневой компонент чудо на хамство, автор таким образом отсылает читателя/пользователя к Библейскому тексту, точнее к тексту Ветхого Завета.

Горе без ума (№ 9 (101) - 2011) - о проблемах жизни без ума в России, сама публикация дополнена фотографиями картин Питера Брейгеля Старшего «Корабль дураков» и «Страна лентяев», которые в данном случае являются ярким медийным компонентом. Семантика меняется на противоположную в результате замены предлога от на предлог без.

Ср.: Горе от ума - название комедии А. С. Грибоедова $(1824)^{17}$.

«Me-me-me» все возрасты покорны. Дмитрий Соколов-Митрич о любви, молодежи и равнодушии (№ 10 (138) - 2014).

В этом примере заменяется базовый компонент КЕ любви на слэнговое слово, набранное латиницей и взятое в кавычки (двойное графическое выделение) «Me-me-те», так как речь идет о проблемах современной молодежи ${ }^{18}$.

Ср.: Любви все возрасты покорны - из романа А. С. Пушкина «Евгений Онегин (гл. 8, строфа $29-1832){ }^{19}$.

Я тебя породил - я тебя и люблю. 4 тезиса для обиженных детей и их родителей (№ 6 (170) - 2017). Благодаря подзаголовку тема статьи понятна, более того, замена глагольного компонента КЕ убью на люблю меняет семантику инварианта на противоположную, так как журнал «Фома» - журнал православный, в публикациях которого транслируются идеи христианства.

Ср.: Я тебя породил, я тебя и убью - цитата из повести Н. В. Гоголя «Тарас Бульба» $(\text { гл. } 9-1835)^{20}$.

Приём лексической субституции остаётся востребованным приёмом модификации устойчивых выражений у журналистов, подтверждая, что КЕ литературного происхождения «является не только номинативной единицей, но

17 MOKIJENKO, V. M. - SEMENEC, O.P. - SIDORENKO, K. P.: «Gore ot uma» A.S. Gribojedova: citaty, literaturnyje obrazy, krylatyje vyraženija: Učebnyj slovar'-spravočnik. SPb.: Izd-vo RGPU im. A. I. Gercena, 2009, s. 82.

18 LOMAKINA, O. V., MAKAROVA, A. S.: Sovremennyj zagolovok kak primer realizacii funkcional'nogo potenciala krylatiki v publicističeskom diskurse. In: TRET’JAKOVA, I. Ju. (red.): Žizn' frazeologii frazeologija v žizni: sbornik naučnych statej k jubileju professora A. M. Melerovič. Kostroma: Izd-vo Kostrom. gos. un-ta, 2018, s. 183.

19 BERKOV, V.P., MOKIJENKO, V. M., ŠULEŽKOVA, S. G.: Bol’šoj slovar' krylatych slov russkogo jazyka: ok. 4 ooo jedinic. Moskva: AST: Astrel': Russkije slovari, 2005, s. 255.

20 Там же, c. 576. 
и оценочно-экспрессивной, реализуя таким образом единство рационального и эмоционального в контексте» ${ }^{21}$.

Первые два примера содержат одну и ту же преобразованную КЕ - герой нашего времени.

Форрест Гамп и герои нашего времени (№ 1 (11) - 2001) - автор статьи размышляет о героях американского кино на примере образа главного героя фильма «Форрест Гамп».

В первом заголовке присутствует экспликация КЕ с грамматическими изменениями, стержневой компонент герой меняется на форму мн. ч. герои. Данная замена позволяет расширить тему публикации и задуматься над героями нашего отечества.

Фарисей как герой нашего времени. О 12-ой главе Евангелия от Матфея (№ $9(161)-2016)$.

Во втором примере происходит комплексное преобразование при помощи экспликации за счёт ввода имени существительного фарисей (фарисеи религиозно-общественное течение в Иудее в эпоху Второго Храма) и сравнительного союза как, в результате чего создается двусоставное предложение. Семантика конкретизируется, а использование имени существительного фарисей как нарицательного (Фарисейство, -а, ср. Поведение фарисея, лицемерие, ханжество $)^{22}$ в образе героя нашего времени характеризует нашу эпоху как эпоху лицемерия и ханжества. Кроме того, здесь присутствует отсылка к Евангельскому тексту (фарисей, Евангелие от Матфея), что является проявлением интертекстуальности, свойственной православному дискурсу.

Ср.: Герой нашего времени - название романа М. Ю. Лермонтова (1840), возможно, навеянное «Рыцарем нашего времени» Н. М. Карамзина ${ }^{23}$.

Отцы и дети: апокалипсис наших дней? (№ 1 (11) - 2001).

Здесь используются сразу три приема трансформации КЕ: контаминация, экспликация и грамматические изменения. Православный автор опирается в тексте на Библейский контекст, создавая таким образом апелляцию к Книге книг. Такое же мнение высказывают авторы Большого словаря крылатых слов русского языка (2005): «Возможно, словосочетание (отцы и дети - прим. O. В., А. С.) навеяно оборотом из Ветхого завета, где он нередко употр., напр.,

21 MAKAROVA, A.S.: Ambivalentnost' funkcional'nogo potenciala krylatogo vyraženija fa - Šarli. Voprosy teorii i praktiki žurnalistiki, № 4, 2017, T. 6, s. 572.

22 Farisejstvo - Tolkovyj slovar' Ožegova - Slovari i Ėnciklopedii. <https://endic.ru/ozhegov/Farisejstvo37576.html>. [online]. [cit. 21. 1. 2020].

23 BERKOV, V.P., MOKIJENKO, V. M., ŠULEŽKOVA, S. G.: Bol'šoj slovar' krylatych slov russkogo jazyka: ok. 4000 jedinic. Moskva: AST: Astrel': Russkije slovari, 2005, s. 119. 
„...так говорит Господь: вот, Я наполню вином до опьянения всех жителей сей земли...и сокрушу их друг о друга, и отцов и сыновей вместе [...]“» ${ }^{24}$.

Ср.: Отцы и дети - назв. романа И. С. Тургенева (1862), где описан конфликт двух поколений людей XIX в. ${ }^{25}$

Ср.: Апокалипсис (греч. - 'откровение') - раннехристианское произведение, приписываемое Иоанну Богослову, последняя книга Нового Завета ${ }^{26}$.

Какой русский не любит быстрой еды? (№ 5 (49) - 2007).

Так называется интервью с управляющим ресторана «Красная площадь, дом 1» Михаилом Зреловым, в котором говорится о философии «фаст-фуда» (от англ. Fast 'быстрый' и Food 'еда') и традициях русской трапезы. Данный комплексный приём включает импликацию инварианта КЕ и лексическую субституцию, которая создаёт языковую игру, построенную на схожести звучания имен существительных езда и еда. Новообразование приобретает ироничный оттенок, семантика меняется: возможно, русские любят не только быструю езду, но и быструю еду?

Ср.: Какой же русский не любит быстрой езды? - цитата из лирического отступления автора в поэме Н. В. Гоголя «Мертвые души» (т. 1, гл. $11-1842)^{27}$.

Красотою спасемся?.. (№ 2 (14) - 2002)

Здесь автор прибегает к синтаксическим изменениям - повествовательное утвердительное предложение преобразуется в вопросительное, изменение формы глагола спасёт на спасёмся содержит апелляцию к Библейскому контексту, изменяется роль стержневого компонента имени существительного красота (им. п.) на красотою (тв. п.), а само новообразование представляет собой имплицированную форму инварианта КЕ. Семантика приобретает оттенок сомнения и неуверенности в отличие от утверждения в инвариантной форме KE.

Ср.: Красота спасёт мир - выражение, которое восходит к роману Ф. М. Достоевского «Идиот» $(1868)^{28}$.

Мертвые души - 3: Небесный Помещик. Что Гоголь на самом деле хотел написать в продолжении поэмы? (№ 5 (169) - 2017).

Публикация представляет собой интервью с доктором филологических наук В. Воропаевым о судьбе второго и третьего томов поэмы «Мертвые души». Сам заголовок преобразован при помощи экспликации КЕ и игры со знаками

24 Там же, с. 359.

25 Там же, с. 358.

26 Там же, с. 29.

27 Там же, с. 213.

28 ŠULEŽKOVA, S. G.: «I žizn', i slezy, i ljubov'...» Proischoždenije, značenije, sud'ba 1500 krylatych slov i vyraženij russkogo jazyka. Moskva: FLINTA: Nauka, 2011, s. 341. 
препинания (тире и двоеточие). Введенный компонент Небесный Помещик подчеркивает то, что Н.В.Гоголь был глубоко верующим человеком, а не морализатором, как учат до сих пор в российских школах. Свою задачу писатель видел, по мнению В. Воропаева, в ответах «на глубочайшие вопросы: в чем суть русского характера, в чем смысл существования русского народа, то есть каков Божий Промысл о русском народе, и какие язвы мешают русскому народу реализовать Божий Промысл, и как эти язвы можно залечить?» ${ }^{29}$.

Ср.: Мертвые души - выражение образовано по назв. поэмы Н. В. Гоголя $(1842)^{30}$.

Приведённые примеры доказывают высказанный тезис: «самым распространённым способом употребления крылатых единиц являются комплексные трансформации, прагматическая цель которых - сделать высказывание экспрессивным, актуализировать информацию, усилить эффект воздействия» ${ }^{31}$.

\section{Выводы}

Очевидно, что из всех композиционных частей медиатекста особая коммуникативная роль отводится заголовку. Данное исследование показало, что православные авторы часто используют КЕ, восходящие к русской литературе, прибегают к различным трансформациям этих устойчивых единиц в прагматических целях, а использование КЕ, появившихся «в художественном тексте отражает популярность и востребованность крылатики в целом и знание художественных текстов в частности» 32 .

Проведенное исследование показало следующее:

1. наиболее частотны выражения, восходящие к творчеству таких писателей, как Н. В. Гоголь (3 примера), М. Ю. Лермонтов (2 примера), Е. Л. Шварц (2 примера). Эти цифры подтверждают мнение О.В. Ломакиной о так называемом шорт-листе КЕ у современных журналистов «как самого употребительного разряда фразеологических ресурсов языка, которые активно используются при выборе заголовков» ${ }^{33}$;

29 Mertvyje duši - 3: Nebesnyj Pomeščik - Pravoslavnyj žurnal «Foma». <https://foma.ru/mertvyiedushi-3-nebesnyiy-pomeshhik.html>. [online]. [cit. 21. 1. 2020].

30 BERKOV, V.P., MOKIJENKO, V. M., ŠULEŽKOVA, S. G.: Bol'šoj slovar' krylatych slov russkogo jazyka: ok. 4 ooo jedinic. Moskva: AST: Astrel': Russkije slovari, 2005, s. 267.

31 LOMAKINA, O.: Realization of the Winged Word Functional Potential in Modern Russian fournalism. Filologija i Kul'tura. Philology and Culture, № 1 (55), 2019, p. 78.

32 LOMAKINA, O. V., NELYUBOVA, N. Yu.: Fictional Text as a Basis for the Internet Meme: Based on the Study of Modern Receptions. Vestnik Tomskogo gosudarstvennogo universiteta, № 437, 2018, p. 43.

33 LOMAKINA, O. V.: K voprosu ob opredelenii koncentra sovremennoj krylatiki. In: BORISOVA, A. S., IGNATENKO, A. V., LARINA, T.V., LOMAKINA, O.V. (red.): IV Firsovskije čtenija. Jazyk 
2. наибольшим трансформационным потенциалом обладает приём комплексного преобразования КЕ, что делает его наиболее востребованным (7 примеров);

3. изменение семантики обнаружено в 6 заголовках из 15 рассмотренных, что продиктовано авторскими интенциями, христианскими ценностями, тематикой публикации;

4. наличие отсылок и апелляций к текстам Библии демонстрирует в очередной раз особую интертекстуальность православного медиадискурса, в связи с чем «представляется необходимым углубленное исследование такой языковой особенности как интертекстуальность религиозного (применительно к нашему исследованию - православного) дискурса» ${ }^{34}$.

\section{Литература:}

BERKOV, V.P., MOKIJENKO, V. M., ŠULEŽKOVA, S. G.: Bol'šoj slovar' krylatych slov russkogo jazyka: ok. 4000 jedinic. Moskva: AST: Astrel': Russkije slovari, 2005. ISBN 5-93259-015-7, ISBN 985-13-4100-2.

BOLSUNOVSKAJA, L. M.: Metadiskurs: traktovki ponjatija i napravlenija issledovanija. In: ROMANOVA, T. V. (red.): Kognitivnyje issledovanija jazyka. Nižnij Novgorod: Izdatel'stvo DEKOM, 2019, s. 667-671. ISBN 978-5-89533-424-9.

Farisei. Vikipedia: svobodnax enciklopedija. <https://ru.wikipedia.org/wiki/Фарисеи>. [online]. [cit. 21. 1. 2020].

Farisejstvo - Tolkovyj slovar’ Ožegova - Slovari i Ėnciklopedii. <https://endic.ru/ ozhegov/Farisejstvo-37576.html>. [online]. [cit. 21. 1. 2020].

KIBRIK, A. A.: Modus, žanr $i$ drugije parametry klassifikacii diskursov. Voprosy jazykoznanija, 2009, № 2, s. 3-21. ISSN 0373-658X (Print).

KUNYGINA, O. V., LOMAKINA, O. V., MAKAROVA, A. S.: Orthodoxy and the World Website as an Example of Modern Religious Discourse. The European Proceedings of Social \& Behavioural Sciences, No 59, p. 507-514. ISSN: 2357-1330. https://doi.org/ 10.15405/epsbs.2019.08.02.41.

v sovremennych diskursivnych praktikach: materialy dokladov i soobščenij Meždunarodnoj naučno-praktičeskoj konferencii. Moskva: RUDN, 2019, s. 264.

34 MAKAROVA, A. S.: Religioznaja jazykovaja ličnost' i religioznaja kartina mira: osobennosti analiza. Vestnik ČGPU im. I. Ja. Jakovleva, № 3 (103), 2019, s. 123. 
LOMAKINA, O.: Realization of the Winged Word Functional Potential in Modern Russian fournalism. Filologija i Kul'tura. Philology and Culture, № 1 (55), 2019, p. 76-79. https://doi.org/10.26907/2074-0239-2019-55-1-76-79.

LOMAKINA, O. V., MOKIENKO, V. M.: Winged words in a modern cultural context. RUDN Journal of Language Studies, Semiotics and Semantics, № 10 (2), p. 256-272. https://doi.org/10.22363/2313-2299-2019-10-2-256-272.

LOMAKINA, O. V., NELYUBOVA, N. Yu.: Fictional Text as a Basis for the Internet Meme: Based on the Study of Modern Receptions. Vestnik Tomskogo gosudarstvennogo universiteta, № 437, 2018, p. 36-44. https://doi.org/10.17223/15617793/437/5.

LOMAKINA, O. V.: $K$ voprosu ob opredelenii koncentra sovremennoj krylatiki. In: BORISOVA, A. S., IGNATENKO, A. V., LARINA, T. V., LOMAKINA, O. V. (red.): IV Firsovskije čtenija. Jazyk v sovremennych diskursivnych praktikach: materialy dokladov i soobščenij Meždunarodnoj naučno-praktičeskoj konferencii. Moskva: RUDN, 2019, s. 259-265.

LOMAKINA, O. V.: Krylatyje jedinicy v roli sovremennogo gazetnogo zagolovka: sostav, tendencii upotreblenija. Russkij jazyk za rubežom, № 1, 2019, s. 37-41. ISSN 0131$-615 \mathrm{X}$.

LOMAKINA, O. V., MAKAROVA, A. S.: Sovremennyj zagolovok kak primer realizacii funkcional'nogo potenciala krylatiki $v$ publicističeskom diskurse. In: TRET'JAKOVA, I. Ju. (red.): Žizn' frazeologii - frazeologija v žizni: sbornik naučnych statej k jubileju professora A. M. Melerovič. Kostroma: Izd-vo Kostrom. gos. un-ta, 2018, s. 180-186. ISSN 978-5-8285-0959-1.

MAKAROVA, A. S.: Ambivalentnost' funkcional'nogo potenciala krylatogo vyraženija fa-Šarli. Voprosy teorii i praktiki žurnalistiki, № 4, 2017, T. 6, s. 566-577. https:// doi.org/10.17150/2308-6203.2017.6(4).566-577.

MAKAROVA, A.S.: Religioznaja jazykovaja ličnost' $i$ religioznaja kartina mira: osobennosti analiza. Vestnik ČGPU im. I. Ja. Jakovleva, № 3 (103), 2019, s. 118-125. https://doi.org/10.26293/chgpu.2019.103.3.016.

MELEROVIČ, A. M., MOKIJENKO, V. M.: Frazeologizmy v russkoj reči: slovar': ok. 1000 jedinic. Moskva: Russkije slovari: Astrel': AST, 2005. ISBN 5-98010-011-3, 5-271-00448-1, 5-17-002939-X.

Mertvyje duši - 3: Nebesnyj Pomeščik - Pravoslavnyj žurnal «Foma». <https:// foma.ru/mertvyie-dushi-3-nebesnyiy-pomeshhik.html>. [online]. [cit. 21.1. 2020].

MOKIJENKO, V. M., SEMENEC, O.P., SIDORENKO, K. P.: «Gore ot uma» A. S. Gribojedova: citaty, literaturnyje obrazy, krylatyje vyraženija: Učebnyj slovar'-spravočnik. $\mathrm{SPb}$.: Izd-vo RGPU im. A. I. Gercena, 2009. ISBN 978-5-8064-1426-8.

ŠULEŽKOVA, S. G.: Krylatyje vyraženija russkogo jazyka, ich istočniki i razvitije. Moskva: «Azbukovnik», 2002. ISBN 5-937860-21-7. 
ŠULEŽKOVA, S. G.: «I žizn', i slezy, i ljubov'...»Proischoždenije, značenije, sud'ba 1500 krylatych slov i vyraženij russkogo jazyka. Moskva: FLINTA: Nauka, 2011. ISBN 978-5-9765-1030-2.

Žurnal Foma. <https://foma.ru/arhiv>. [online]. [cit. 10. 5. 2020].

\section{About the authors}

\section{Svetlana Viktorovna Dudushkina}

Moscow State Pedagogical University, Institute of Foreign Languages, Moscow, Russian Federation

Sepia3@yandex.ru

\section{Olga Valentinovna Lomakina}

St. Tikhon's Orthodox University, Faculty of Philology, Department of General Linguistics and Slavistics, Moscow, Russian Federation

Peoples' Friendship University, Faculty of Philology, Department of Foreign Languages, Moscow, Russian Federation

rusoturisto07@mail.ru

\section{Alexandra Stefanovna Makarova}

St. Tikhon's Orthodox University, Faculty of Philology, Department of General Linguistics and Slavistics, Moscow, Russian Federation

Moscow Polytechnic University, Graduate School of Press and Media Industry, Moscow, Russian Federation

aleste_63@mail.ru 